Голышкина Л.А. Текстообразование как ориентировочная деятельность...

УДК 81'23: 808, 81’42 / DOI 10.30982/2077-5911-2020-43-1-23-35

\author{
ТЕКСТООБРАЗОВАНИЕ КАК \\ ОРИЕНТИРОВОЧНАЯ ДЕЯТЕЛЬНОСТЬ: \\ ОПЫТ ЭКСПЕРИМЕНТАЛЬНОГО ИССЛЕДОВАНИЯ
}

Голышкина Людмила Александровна

доцент кафедры филологии

факультета гуманитарного образования, декан факультета повышения квалификации

Новосибирского государственного

технического университета

Россия, 630073, Новосибирск, пр. К. Маркса, 20

Ludmila200273@mail.ru,lag@fpk.nstu.ru

Статья посвящена осмыслению деятельностной природы текстообразования. Теоретико-методологической основой исследования выступает психологическая концепция ориентировочной деятельности, вводящая в сферу лингвистики такие понятия, как ориентировочная основа действия, а также автоматические и активные действия. В статье представлены поэтапное описание эксперимента, демонстрирующего понимание текстообразования как ориентировочной деятельности, и его результаты, осуществлена интерпретация полученных данных. Эксперимент реализует идею трансформации действия в деятельность путем изменения мотивации испытуемых. Методика эксперимента основана на замещении автоматических текстообразующих действий активными: испытуемые создают тексты согласно задаваемым ориентировкам, что имеет деятельностный характер. При этом на первом этапе эксперимента текстообразование осуществляется без задаваемой ориентировки, имеет статус действия. На втором этапе ориентировкой выступает коммуникативная цель, осмысляемая субъектом речи. На третьем этапе - образ адресата. Предлагаемые испытуемым стимулы выступают в качестве базовых составляющих модели коммуникативного контекста, трактуемой в качестве ориентировочной основы действия, определяющей образ типа текста в сознании продуцента. Результаты исследования свидетельствуют, что такая ориентировка, как коммуникативная цель, выступает катализатором выраженной диалогичности, информативности и аргументированности - свойств, характеризующих тексты риторического типа, нацеленные на персуазивный эффект в коммуникативной практике. Коммуникативная цель предстает как ведущая ориентировка, превращающая действие в деятельность. Ориентировка продуцента на образ адресата обнаруживает эгоцентрическую природу текстообразования, являющуюся следствием проявления в мыслеречевой деятельности субъективности как основополагающего свойства языка. Реализованная экспериментальная процедура может быть использована для развития методики планомерного формирования текстообразующей деятельности.

Ключевые слова: текстообразование, модель коммуникативного контекста, ориентировочная основа действия, мотив, автоматическое действие, активное действие, ориентировочная деятельность, коммуникативная цель, образ адресата 


\section{Введение}

Цель настоящей статьи заключается в демонстрации результатов эксперимента, проводимого автором настоящей статьи в течение 2018-2019 гг. и направленного на изучение т. н. риторического текстообразования, представляющего собой поэтапный технологический процесс «переливания мысли в слово» (Л.С. Выготский), регулируемый коммуникативной ситуацией.

Осмысление текстообразования, его единиц и принципов, находящихся в исследовательском поле риторики и лингвистики текста, не мыслится сегодня без обращения к методологии психологии, в частности к теории планомерного (поэтапного) формирования умственных действий, где особое внимание уделяется феномену ориентировочной деятельности [Гальперин 1954, 1957, 1958, 2007; Запорожец 1960; Леонтьев 1997; Подольский 1979, 1987; Талызина 1975].

Сама концептуальная идея ориентировки как «заданного результата», «модели потребного будущего» (Н.А. Бернштейн), «образа результата» (А.А. Леонтьев), «ориентировочного образа действия» (П.Я. Гальперин) оказывается релевантной для риторической теории текстообразования, постулирующей осознанный технологический подход к построению текста, призванный обеспечить его эффективность в коммуникативной практике.

Описываемый эксперимент преследовал цель демонстрации деятельностной природы текстообразования путем актуализации ряда стратегических риторических ориентиров, или «ориентировочных раздражителей» (П.Я. Гальперин), организующих структуру коммуникативного акта.

Результаты эксперимента имеют предварительный характер и актуальны для дальнейшего выяснения механизмов текстообразования, в частности для выявления мотивационной основы речевого действия, для диагностирования активных и автоматических действий субъекта речи, их соотношения в практике текстовой деятельности, а также для обнаружения технологических коммуникативно-речевых сбоев при непонимании ориентировки того или иного уровня.

\section{Теоретические основания эксперимента}

Настоящее исследование инициировано концепцией П.Я. Гальперина об ориентировочной деятельности субъекта, которая трактуется как «средство приспособления к ситуациям, которые отличаются от условий работы механизмов, управляющих автоматическими реакциями. Все такие ситуации характеризуются одним общим признаком, точно указанным И.П. Павловым, признаком новизны. Этот признак, как своеобразный раздражитель, вызывает рассогласование с нервной моделью прошлого опыта, рассогласование выключает механизмы автоматического реагирования и включает механизмы деятельности по ориентировке в ситуации на основе ее психического отражения» [Гальперин 2007: 134].

Возможность проецирования психологической теории на текстообразование связано с переосмыслением таких понятий, как ориентировочная основа действия (далее ООД - Л. Г.), а также автоматические и активные действия.

Так, ООД - это «представления о том, на что следует ориентироваться, чтобы правильно выполнить действия» [Гальперин, Пантина 1957: 44]. Вслед за П.Я. Гальпериным, ООД понимается исследователями как «план, проект действия, которое составляется на первом этапе его формирования и в дальнейшем участвует в регуляции действий, определяя их качество» [Лидерс, Фролов 2012: 17]. 
Голышкина Л.А. Текстообразование как ориентировочная деятельность...

В практике текстообразования в качестве ООД можно рассматривать такую регулирующую наши представления о тексте когнитивную структуру, как модель коммуникативного контекста (далее МКК - Л. Г.). Так, согласно Т. ван Дейку, чтобы построить текст, люди должны хранить в памяти МКК, содержащую информацию об участниках речевой коммуникации, их целях, о типе социальной ситуации, к которой должен быть приложим строящийся текст. При этом контекстная модель контролирует как стиль, так и содержание, определяет информацию о ситуации, которая может быть передана в тексте, и, наконец, указывает на то, какой тип текста должен быть построен [Дейк ван 2015: 170]. МКК представляет собой специфический тип ситуационной модели как структуры представления знаний, репрезентирующей коммуникативную ситуацию [Там же: 276], прототипическим основанием которой выступает коммуникативный акт, подробно описанный в различных концепциях моделирования коммуникации [Shannon 1948; Lasswell 1948; Якобсон 1985; Городецкий 1989].

По сути, МКК, трактуемая как ориентировочная основа, задающая схему объекта действия, воплощает представления об образе того текстотипа, который должен быть создан с учетом конституентов коммуникативного акта: адресанта, его коммуникативной цели, адресата, обстоятельств общения, канала передачи информации и т. п.

Для выявления механизмов риторического текстообразования, постулирующего принципы осознанности и целенаправленности, а также диалогичности коммуникативного взаимодействия, в качестве ориентировок стратегического характера выдвигаются такие параметры, как коммуникативное целеполагание продуцента и моделируемый им образ адресата.

Кроме того, для практики текстообразования представляется релевантной идея выделения автоматических и активных действий. Так, если «действие опирается на готовые механизмы, включая и механизмы его регуляции, оно является автоматическим. Если же действие следует таким отношениям наличной ситуации, путем ориентировки в плане образа, то оно является активным» [Гальперин 2007: 124]. Здесь важно отметить, что «ориентировка в плане образа составляет условие не только активных реакций, но и увязки их с реакциями автоматическими или автоматизированными. $<$... $>$ Автоматические механизмы включаются в состав активных целенаправленных действий там, где в их составе выделяются и узнаются знакомые части» [Там же: 126-127].

Концепция дифференциации действия коррелирует с психолингвистической теорией мотивации. Так, с общеметодологических позиций выделяют две группы мотивов общения: 1) лежащие за пределами общения, когда общение подчинено производственной в широком смысле деятельности и обладает статусом действия; 2) перешедшие на одну из целей общения, когда общение побуждается собственным мотивом и превращается в деятельность [Тарасов 2009: 144].

Таким образом, мотивы первой группы инициируют по преимуществу автоматические действия. Мотивы второй группы активируют образ результата действия, в частности образ определенного текстотипа в сознании субъекта текстообразования. Здесь активное действие может быть истолковано в качестве условия трансформации действия в деятельность.

Рассмотренные теоретические положения позволяют сформулировать гипотезу, которая верифицируется экспериментальной частью исследования: превращение действия в деятельность основывается на замещении автоматического действия активным путем осмысления субъектом речи базовых составляющих МКК, таких как коммуни- 
кативная цель и образ адресата, используемых в качестве текстообразующих ориентировок стратегического уровня.

\section{Описание эксперимента}

Эксперимент состоял из 3 этапов и предполагал пошаговое осмысление испытуемыми последовательно задаваемых ориентировок текстообразования и их вербализацию.

Испытуемые - студенты-бакалавры факультета гуманитарного образования Новосибирского государственного технического университета (182 человека).

На первом этапе эксперимента испытуемым предлагалось в течение ограниченного времени (5 минут) создать текст на определенную, понятную всем тему («Новосибирск осенью/зимой/весной» - в зависимости от реального времени проведения эксперимента) без каких бы то ни было дополнительных установок со стороны инициатора эксперимента. Иначе говоря, задаваемая текстообразующая ориентировка отсутствует.

На втором этапе участникам задавался выбор коммуникативной цели (убеждающая, информационная, развлекательная, фатическая), согласно которой они моделировали новую версию текста на ту же тему в том же временном режиме. Ориентировка - коммуникативная цель.

На третьем этапе эксперимента текстообразующее задание реализовывало на тех же условиях задачу вербализации образа адресата с сохранением уже осознанной коммуникативной цели. Задаваемая ориентировка - адресат.

Получено в течение 2018-2019 гг. 520 экспериментальных текстов, зафиксированных в письменной форме.

\section{Обсуждение хода эксперимента}

Первая попытка, связанная со сбором спонтанных текстов, демонстрирует включение у испытуемых автоматизированных механизмов текстообразования. Она оказывается подчиненной производственной, в нашем случае учебной, деятельности и обладает статусом действия вследствие ее внешней директивности, спонтанности в определении испытуемыми своего коммуникативного целеполагания, что сопряжено еще и с фактором временной ограниченности итерации текстообразования.

Анализ полученных результатов первого этапа текстообразования позволяет в качестве примера типовых текстов, созданных испытуемыми, привести следующие:

Зимы в Новосибирске очень холодные, снежные и долгие, а также очень красивые. Снег идет крупными хлопьями и покрывает весь город. Особенно красиво рано утром, когда в городе еще нет людей и машин ${ }^{1}$ (экспериментальный текст 1 - далее ЭТ в порядке следования. - Л. Г.).

На улице становится теплее, начинает сходить снег, это значит, что в город пришла весна. Люди переодеваются в легкую одежду, снимают тяжелые шубы и сапоги, а вместе с ними и свое грустное настроение. Все больше горожан выходит на улииу. Можно заметить, что для всех это глоток свежего воздуха (ЭТ 2).

Более чем в 70 \% полученных текстов испытуемые представляют объект в фокусе стандартного набора устойчиво связываемых с определенным временем года сезонных характеристик, прибегая к такому функционально-смысловому типу речи, как описание.

\footnotetext{
1 Здесь и далее в приводимых экспериментальных текстах сохраняется орфография и пунктуация оригинала. - Л. Г.
} 
Голышкина Л.А. Текстообразование как ориентировочная деятельность...

Несмотря на навязанность участникам эксперимента речевого действия, некоторые испытуемые все же демонстрируют речетворческие потенции и идиостилевое своеобразие, например, используя прием аналогии:

Новосибирск весной похож на девушку, на очень капризную, но любимую... (ЭТ 3) или Весной Новосибирск становится похож на жизнь в России. Непредсказуемость, неадекватность преследует пешеходов на протяжении всего пути. Вот один день светит, на первый взгляд, летнее солнце, а на другой тебя сносят с ног жестокие порывы зимнего ветра (ЭТ 4).

В 32 \% полученных текстов мы отмечаем субъективацию повествования. Так, в ряде текстов обнаруживаем средства выражения субъективной эпистемической модальности, формирующие суждения с семантикой проблематической достоверности, свидетельствующие об экспликации точки зрения говорящего:

Снег, дождь, ветер, наледь - это новосибирская весна! Столииу Сибири, наверное, очень любит самое холодное время года! Не хочет отпускать город в тепло (ЭТ 5); $<\ldots>$ в Новосибирске обновление жизни ошущается несколько по-другому - более торжественно и быстро. Возможно, это связано с ожиданием этого времени года, $а$, возможно, и с самим городом, который как будто оживает вместе с заснувшей природой (ЭТ 6); Весна, как мне кажется, для любого города-особое время (ЭТ 7).

Кроме того, прибегают испытуемые и к ядерным средствам субъективации - к использованию т. н. я-/мы-высказываний, наделяющих тексты эгоцентричностью:

Я люблю весну, а Новосибирск весной тем более <..> (ЭТ 8); <..> Мы одни из первых встречаем морозы, переживаем сорокаградусную отметку на термометре и остаемся в любимом городе (ЭТ 9); <..> Мы смотрим на календари с чувством, что вот-вот нагрянет тепло, распустятся первые листья на деревьях, а за окном... сугробы. Это неплохо. За это я и люблю свой город (ЭТ 10).

Вторая попытка текстообразования нацелена на активацию текстообразующих действий, а именно на самостоятельное осмысление субъектом речи коммуникативной цели текста - важнейшей составляющей МКК и, соответственно, ООД. Отметим, что по нашей просьбе все испытуемые в качестве предтекстового комментария письменно указывали коммуникативную цель конструируемого ими текста.

Следование такой ориентировке наделяет репрезентативную часть текстов эксплицитной диалогичностью, адресованностью, повышает уровень авторской модальности, усиливает информативно-содержательный потенциал текстов, что способствует в большинстве случаев и увеличению их объема:

Цель убеждаюшая.

Многие не любят осень, а осень в Новосибирске и вовсе кажется большинству его жителей абсолютно безрадостной и тоскливой. Это совсем не так. Я вам расскажу.

Сентябрь у нас очень красивый. Это буйство красок в парках, от еще неувядшего зеленого до начинающего проступать красного. Это время долгих прогулок в теплую погоду по иентру города, от площзади Ленина по оживленной Вокзальной магистрали.

А октябрь? Октябрь в нашем городе очень уютньй. Становится холоднее, и все ждут снега, а когда он наконеи выпадает, легкий, робкий, люди радуются и надеятся, что он не растает. И все такое белое, нарядное... Ну разве это не красота? (ЭТ 11).

Коммуникативная цель как ориентировка в плане образа моделируемого текста выступает своего рода катализатором аргументированности текста. Так, эксплицируя убеждающую коммуникативную цель, некоторые испытуемые выстраивают текст по 
дедуктивному принципу, актуальному для рассуждения: сначала вводится тезис, затем выстраивается система аргументов в поддержку истинности тезиса, делается вывод. Например:

Весна в Новосибирске - самое кочмарное из того, что могла придумать природа (тезис). Весь март идет снег, а на дорогах - грязь, которую никто не спешит убирать (аргумент 1). Апрель - пыльный, сухой и ветренный месяи, когда непонятно, как одеваться, отчего новосибириьь чаще болеют (аргумент 2). Май-настоящий ад для аллергиков (аргумент 3). Ничего хорочего в весне нет, в отличие, например, от лета (вывод) (ЭТ 12);

$<\ldots>$ Осень в Новосибирске - одно из лучших времен года (тезис). Во-первых, это неописуемая красота природы, завораживающая пестрота деревьев в парках и на улицах (аргумент 1). Во-вторых, осень - это начало нового учебного года, нового ичикла, который всегда встречают с торжеством (аргумент 2) (ЭТ 13).

Третья итерация текстообразования связана с активацией такой ориентировки, как образ адресата, призванной сформировать адресность текста с учетом сохранения уже осознанной на предыдущем этапе коммуникативной цели. Номинация адресата так же фиксировалась испытуемыми в виде предтекстового комментария. Так, в качестве адресатов чаще всего указывались: друг/подруга, мама, бабушка, одногруппница, родственники либо гости/туристы (иногда с указанием места жительства, например, из Санкт-Петербурга или из Якутии); реже - возрастные группы, например, cmуденты, школьники и дошкольники; дважды - мэр Новосибирска; единичные случаи - Президент России, а также Стивен Кинг:

Уважаемый Стивен Кинг, меня всегда поражало ваше мастерство анализировать человеческие страхи и грамотно описывать их в своих произведениях. Я приглашаю посетить вас Россию в середине весны. Приезжайте в Новосибирск и, я полагаю, вы найдете себе гору незабываемых ошущений, которые легко можно включить в вашу книгу без малейших преукрас (ЭТ 14).

Ориентировка на образ адресата актуализировала в среде испытуемых жанры обращения (например, к мэру г. Новосибирска Анатолию Локтю, Президенту России или москвичам, которые жалуются на качество жизни) и приглашения (Стивена Кинга, родственников, друзей и т. п.), а также жанр письма, столь мало используемый сегодня молодежью в условиях тотальной гаджетизации. Именно этот комплексный по своей коммуникативной природе жанр продемонстрировал хотя и немногочисленные, но, тем не менее, наиболее удачные примеры текстоообразования, характеризующиеся корректным соотношением заявляемой коммуникативной цели и типа адресата, оптимальным соотношением средств авторизации и адресации, информативностью.

Ориентировка на определенного адресата обусловила речетворческую интенцию некоторых испытуемых трансформировать стандартный монолог в диалог с имплицитной ответной реакцией. При этом мы наблюдаем усложнение синтаксической организации текстов, в ряде случаев - «подгонку» речевых средств под речемыслительные возможности воображаемого реципиента путем использования элементов просторечия и разговорной лексики, как например:

Адресат - дошкольники

А вы знаете, как прекрасен наш город весной? Возможно, немного холодно - в Москве-то поди уже и снег в марте растаял, а в Сочи так и загорать можно. Зато у 
Голышкина Л.А. Текстообразование как ориентировочная деятельность...

нас вон - капели звучат, птицы всякие. Сльцшали когда-нибудь? А прислушивались? А лужи-то у нас какие - прыгай по ним - сколько хочешь, аж корочка ледяная хрустит. $B$ Москве-то такого уж давно нет. А мы-то ведь счастливы. Правда? (ЭТ 15).

Укажем, что в погоне за стимулируемой адресацией нередко снижается объем текста, его информативные качества.

Важно отметить, что ориентировка на образ адресата, как ни парадоксально, способствует росту субъективации повествования, усилению авторского «Я» в ряде текстов. Так, адресуя текст другу, испытуемый практически забывает о нем как о субъекте взаимодействия, минимизируя средства адресации и наделяя текст выраженной эгоцентричностью:

Я была на днях на конщерте Би-2! Ты представить не можешь, как это круто! До концерта я всю весну ходила подавленная, наверное, у меня была весенняя хандра, но как-только я посетила кониерт, почувствовала весну и ее запах. Да-да, именно запах, запах нового и прекрасного. Видимо, все дело в восприятии (ЭТ 16).

Более того, мы фиксируем и случаи полного игнорирования адресата, как например, в смоделированной ситуации общения дочери с родителями:

Я наконец-то выздоровела и скоро начну тренировки на улище. В Новосибирске достаточно тепло, асфальт появляется из-под снега. Мы открыли дачный сезон: я ездила с бабушкой на дачу и помогала ей делать уборку после зимы. Пришлось навести порядок еще и на грядках. Весной хочется много гулять, но я уже начала готовиться к сессии. На майские праздники обязательно приеду в гости (ЭТ 17).

Здесь мы отмечаем уход испытуемых от заявленной темы, переключение продуцентов на эгоцентрическое повествование, нивелирование интеракции.

Систематизируем сделанные в ходе эксперимента наблюдения и представим его результаты.

\section{Результаты эксперимента}

Этап I (задаваемая ориентировка отсутствует, действия автоматические):

- доминирование типовых текстов, содержащих стандартное, основанное на устойчиво воспроизводимых характеристиках, описание объекта, а именно определенного времени года, - в более чем 70 \% от общего количества полученных реакций;

- частичная субъективация повествования: экспликация авторского «Я/Мы» и средств выражения эпистемической модальности - 32 \%.

Этап II (задаваемая ориентировка - коммуникативная цель, действия активные, трансформирующиеся в деятельность):

- наблюдение в текстах всплеска диалогичности, адресованности (преимущественно в убеждении) - $42 \%$;

- усиление информативности и аргументативности текстов, как следствие - увеличение их объема.

Этап III (задаваемая ориентировка - адресат, действия активные, трансформирующиеся в деятельность):

- оформление текстов в виде жанров письма, обращения, приглашения, при этом жанр письма - наиболее продуктивный для полноценного воплощения заданной ориентировки;

- доминирование авторизации при ожидаемой согласно ориентировке адресации $28 \%$;

- наблюдение случаев структурной трансформации монолога в имплицитный диалог; 
- снижение информативности в погоне за адресацией, что нередко сопряжено и с сокращением объема текста;

- фиксация случаев ухода от заявленной темы текста, обусловленного увлеченностью воспроизведением собственного «Я» и центрацией автора.

\section{Интерпретация полученных данных}

Проведенный эксперимент верифицирует положение о том, что текст является источником информации о самом коммуникативном акте. Неслучайно Е.Ф. Тарасов, трактуя текст как превращенную форму реальной действительности, отмечает, что в тексте, помимо собственно передаваемого сообщения, есть информация, которая «закодирована в языковых знаках ... и ... позволяет косвенным образом на основе анализа текста получить сведения о самом коммуникативном акте и его элементах» [Тарасов 2009: 104]. Эта мысль обусловливает потребность теоретико-методологического развития такой области знания, как риторика декодирования, направленной на реконструкцию механизмов текстообразования в направлении «коммуникативный акт - МКК - образ типа текста - текстообразующий замысел».

Результаты эксперимента позволяют трактовать коммуникативный акт как условие превращения действия в деятельность, поскольку, являясь прототипическим основанием МКК, он включается в состав ООД, обеспечивающей построение необходимого продуценту типа текста.

Активация на втором этапе эксперимента такой ориентировки, как коммуникативная цель, продемонстрировала ее потенциал в качестве катализатора выраженной диалогичности, информативности и аргументированности. Указанные параметры в том или ином виде входят в систему типологических свойств т. н. риторического текста [Земская, Качесова, Панченко, Чувакин 2000; Голоднов 2010; Голышкина 2015], нацеленного на планомерное создание персуазивного эффекта, на акциональность и результативность в коммуникативной практике. Таким образом, ориентация на воплощение коммуникативной цели наделяет текст действенностью, подключая к автоматическим действиям продуцента действия активные. Соответственно, мы рассматриваем коммуникативную цель в качестве ведущего ориентира, запускающего механизм превращения действия в деятельность.

Третий этап эксперимента выявил определенные трудности актуализации в текстах образа адресата как заданной ориентировки. Такой результат мы объясняем как условиями проведения эксперимента, так и самой природой текстообразования.

Во-первых, очевидно, что выделенный на создание текста лимит времени (5 минут) при усложнении текстообразующих задач не позволил испытуемым реализовать в полной мере установку на учет «фактора адресата» (Н.Д. Арутюнова), сделать тексты максимально адресными. Заданные временные рамки оказались малы. Это наблюдение свидетельствует о том, что сами по себе активные действия субъекта речи не допускают механистического продуцирования, требуют осознанного подхода без временной регламентации.

Во-вторых, наблюдаемые случаи подмены адресации авторизацией, рост субъективации повествования при реализации стратегии адресации подтверждают мысль об эгоцентричности текстообразования. Еще Э. Бенвенист, рассуждая о природе языка и коммуникации, отмечал, что «именно в языке и благодаря языку человек конституируется как субъект, ибо только язык придает реальность, свою реальность, которая есть 
Голышкина Л.А. Текстообразование как ориентировочная деятельность...

свойство быть, - понятию "Еgo" - “мое я” (здесь и ниже курсив оригинала. - Л. Г.) [Бенвенист 2002: 293]». В свою очередь, по мнению ученого, «“субъективность” ... есть не что иное, как проявление в человеке фундаментального свойства языка. Тот есть “еgо", кто говорит "еgо"» [Там же: 294].

Подобную оценку природе языка дает и И.А. Мельчук в работе «Язык: от смысла к тексту»: «Естественный язык очень “эгоцентричен” - в том смысле, что большое количество языковых знаков особым образом кодируют точку зрения “я” (т. е. Говорящего - того, кто произносит рассматриваемый текст в данном речевом акте); точка зрения адресата языком не кодируется практически никогда. Эта эгоцентричность проявляется самыми разнообразными способами и в словаре, и в грамматике» [Мельчук 2012: 23].

Таким образом, текстообразование, эксплуатируя естественный язык в качестве инструмента своей объективации, перенимает свойство языковой эгоцентричности. А говорящий, в свою очередь, определяет в коммуникации свое место на шкале демонстрации субъективности. Чем выше уровень коммуникативной компетентности субъекта речи, тем свободнее он курсирует по этой шкале, выбирая наиболее уместную в том или ином речевом акте позицию. Именно это положение актуализирует потребность оценки сформированности текстообразующих навыков продуцента, его владения своим языковым «Еgo» как инструментом эффективного коммуникативного позиционирования.

Сделанные в ходе эксперимента наблюдения над мыслеречевым потенциалом испытуемых обусловливают необходимость различения в текстообразовании уровней ориентировки - стратегического, тактического и операционально-технического [Лидерс, Фролов 2012: 20-21]. Использование уровневого подхода, с нашей точки зрения, позволит корректно объяснять неоднократно наблюдаемые ситуации, когда продуцент формулирует коммуникативную цель, но способы и средства ее выражения ей не соответствуют. Или субъект речи осознает стратегию диалогичности, пытается прибегнуть к тактике адресации, но последовательной и планомерной реализации определенных средств воплощения тактики мы не наблюдаем, что свидетельствует об ориентировочных сбоях операционально-технического уровня.

\section{Выводы}

Представленное исследование демонстрирует практику переосмысления психологической теории планомерного (поэтапного) формирования умственных действий и ее методологическую проекцию на теорию текстообразования. Так, использование концепции ориентировочной деятельности позволяет ввести в исследовательский арсенал лингвистики такие понятия, как ООД, а также автоматические и активные действия.

Исследование базируется на понимании текстообразования как ориентировочной деятельности, где текстоформирующими стимулами, или «ориентировочными раздражителями», выступают компоненты МКК, которая рассматривается в качестве ООД.

Выдвижение в эксперименте в функции ориентировок риторического текстообразования таких составляющих МКК, как коммуникативная цель и образ адресата, обусловлено риторическими принципами осознанности, целенаправленности и диалогичности, воплощающими идеологию эффективного текста.

Проведенный эксперимент подтверждает сформулированную гипотезу о механизмах превращения действия в деятельность в части активации коммуникативной цели как ориентировки, следование которой формирует мотивацию текстообразования, в 
той или иной степени регулирует качество текста, определяет информативные и аргументативные свойства текста, обеспечивающие его персуазивные возможности.

Ориентация продуцента на образ адресата обнаруживает эгоцентрическую природу текстообразования, являющуюся следствием проявления в мыслеречевой деятельности человека субъективности как основополагающего свойства языка.

Интерпретация результатов эксперимента свидетельствует о том, что задаваемые ориентировки в плане образа типа текста, такие как коммуникативная цель и образ адресата, относятся к ориентировкам стратегического уровня, что открывает перспективы исследования тактического и операционально-технического ориентировочных уровней, отвечающих за выбор конкретного речевого действия в актуальной коммуникативной ситуации, за адекватность способа его выполнения.

Реализованная в ходе эксперимента процедура превращения действия в деятельность путем поэтапного погружения ментального текстового конструкта в определенную коммуникативную ситуацию может быть использована для развития методики планомерного формирования текстообразующей деятельности.

\section{Литература}

Бенвенист Э. Общая лингвистика. 2-е изд. М.: Едиториал УРСС, 2002. 448 с.

Гальперин П.Я. Введение в психологию. 7-е изд. М.: КДУ, 2007. 336 с.

Гальперин П.Я. Опыт изучения формирования умственных действий // Доклады на совещании по вопросам психологии. 3-8 июля 1953 г. М.: Изд-во Академии педагогических наук РСФСР, 1954. С. 188-201.

Гальперин П.Я. Типы ориентировки и типы формирования действий и понятий // Доклады Академии педагогических наук РСФСР. 1958. № 2. С. 75-78.

Гальперин П.Я. Умственное действие как основа формирования мысли и образа // Вопросы психологии. 1957. № 6. С. 58-69.

Гальперин П.Я., Пантина Н.С. Зависимость двигательного навыка от типа ориентировки в задании // Доклады Академии педагогических наук РСФСР. 1957. № 2. С. 43-46.

Голоднов А.B. Аргументативная структура риторического (персуазивного) текста // Вестник Иркутского государственного университета. 2010. № 1 (9). С. 109-114.

Гольшикина Л.А. Система типологических свойств риторического текста // Мир русского слова. 2015. № 3. С. 31-37.

Городецкий Б.Ю. Компьютерная лингвистика: моделирование языкового общения // Новое в зарубежной лингвистике. Вып. 24. Компьютерная лингвистика. М.: Прогресс, 1989. С. 5-31.

Дейк ван Т.А. Язык. Познание. Коммуникация. 2-е изд. М.: ЛЕНАНД, 2015. 320 с.

Запорожеи А.B. Развитие произвольных движений. М.: Изд-во Академии педагогических наук РСФСР, 1960. $431 \mathrm{c}$.

Земская Ю.Н., Качесова И.Ю., Панченко Н.В., Чувакин А.А. Основы общей риторики. Барнаул: Изд-во Алтайского университета, 2000. 110 с.

Леонтьев А.А. Психология общения. 2-е изд., испр. и доп. М.: Смысл, 1997. 365 с.

Лидерс А.Г., Фролов Ю.И. Развитие представлений об ориентировке и ориентировочной деятельности в концепции П.Я. Гальперина // Культурно-историческая психология. 2012. Т. 8. № 4. С. 13-27.

Мельчук И.А. Язык: от смысла к тексту. М.: Языки славянской культуры, 2012. 176 с. 
Голышкина Л.А. Текстообразование как ориентировочная деятельность...

Подольский А.И. Интеллект в системе ориентировочной деятельности // Психологические исследования интеллектуальной деятельности / Под ред. О.К. Тихомирова. М., 1979. С. 204-210.

Подольский А.И. Функциональное развитие познавательной деятельности в условиях ее планомерного формирования: дис. ... д-ра психол. наук: 19.00.07. М., 1987. $450 \mathrm{c}$.

Тальзина Н.Ф. Управление процессом усвоения знаний. М.: Изд-во МГУ, 1975. $344 \mathrm{c}$.

Тарасов Е.Ф. К построению теории речевой коммуникации // Теоретические и прикладные проблемы речевого общения. М.: ЛИБРОКОМ, 2009. С. 5-147.

Якобсон Р.О. Речевая коммуникация; Язык в отношении к другим системам коммуникации // Избранные работы. М.: Прогресс, 1985. С. 319-330.

Lasswell, H.D. (1948). The Structure and Function of Communication in Society // The Communication of Ideas. New York: Harper and Brothers, Pp. 37-51.

Shannon, C.E. (1948). The Mathematical Theory of Communication // The Bell System Technical Journal. July, Vol. 27. No. 3. Pp. 379-423.

\title{
PRODUCING TEXTS AS ORIENTATION ACTIVITY: EXPERIMENTAL RESEARCH
}

\author{
Lyudmila A. Golyshkina \\ Associate Professor of the Philology Department \\ of the Faculty of Humanities, \\ Dean of the Continuing Education Faculty \\ Novosibirsk State Technical University \\ Russia, 630073, Novosibirsk, 20 pr. K. Marksa \\ Ludmila200273@mail.ru,lag@fpk.nstu.ru
}

The paper is devoted to the understanding of an activity-oriented character of text production. The theoretical and methodological basis of the study is a psychological concept of orientation activity, which introduces into linguistics such concepts as an orientation basis of actions as well as automatic and active actions. The paper presents a step-by-step description of the experiment that demonstrates producing texts as orientation activity, and its results and discussion. The experiment proves the idea of transforming action into activity by changing the motivation of its participants. The method is based on the replacement of automatic text-producing actions by active ones: the participants create texts according to the given orientations, which is activity-oriented. During the first stage of the experiment, texts are produced without any specified orientation, having the status of an action. During the second stage, the orientation is a communicative goal comprehended by the subject of speech. During the third stage that is an image of the addressee. The stimuli offered to the participants act as the basic components of a model of the communicative context interpreted as an orientation basis of actions determining the image of the text type in the mind of its producer. The results of the research show that such orientation as a communicative goal acts as a catalyst for expressing values of conversation, message and argumentation which characterize rhetorical texts aimed at producing a persuasive effect in communicative 
practice. The communicative goal appears to be the leading orientation that turns action into activity. The orientation of the producer to the image of the addressee reveals the egocentric nature of the text production resulted from subjectivity in thoughts-to-speech activity as a fundamental property of the language. The implemented experimental procedure can be used to develop a method of systematic text producing activity.

Keywords: text production, model of communicative context, orientation basis of actions, motive, automatic action, active action, orientation activity, communicative goal, image of the addressee

\section{References}

Benvenist E. Obshchaya lingvistika [General Linguistics]. 2-e izd. Moscow: Editorial URSS, 2002. 448 s. (In Russian).

Gal'perin P.Ya. Vvedenie v psikhologiyu [Introduction to Psychology]. 7-e izd. Moscow: KDU, 2007. 336 s. (In Russian).

Gal'perin P.Ya. Opyt izucheniya formirovaniya umstvennykh deystviy [Experience in the study of the formation of mental actions]. Doklady na soveshchanii po voprosam psikhologii [Psychology Meeting Reports]. 3-8 iyulya 1953. Moscow: Izd-vo Akademii pedagogicheskikh nauk RSFSR, 1954. S. 188-201. (In Russian).

Gal'perin P.Ya. Tipy orientirovki i tipy formirovaniya deystviy i ponyatiy [Types of orientation and types of formation of actions and concepts]. Doklady Akademii pedagogicheskikh nauk RSFSR [Reports of the Academy of Pedagogical Sciences of the RSFSR], 1958, no. 2. S. 75-78. (In Russian).

Gal'perin P.Ya. Umstvennoe deystvie kak osnova formirovaniya mysli i obraza [Mental action as the basis for the formation of thought and image]. Voprosy psikhologii [Psychology Issues], 1957, no. 6. S. 58-69. (In Russian).

Gal'perin P.Ya., Pantina N.S. Zavisimost' dvigatel'nogo navyka ot tipa orientirovki $\mathrm{v}$ zadanii [The dependence of motor skill on the type of orientation in the task]. Doklady Akademii pedagogicheskikh nauk RSFSR [Reports of the Academy of Pedagogical Sciences of the RSFSR], 1957, no. 2. S. 43-46. (In Russian).

Golodnov A.V. Argumentativnaya struktura ritoricheskogo (persuazivnogo) teksta [Argumentative structure of rhetorical (persuasive) text]. Vestnik Irkutskogo gosudarstvennogo universiteta [Bulletin of the Irkutsk State University], 2010, no. 1 (9). S. 109-114. (In Russian).

Golyshkina L.A. Sistema tipologicheskikh svoystv ritoricheskogo teksta [System of the typological features of the rhetorical text]. Mir russkogo slova [World of Russian Word], 2015, no. 3. S. 31-37. (In Russian).

Gorodetskiy B.Yu. Komp'yuternaya lingvistika: modelirovanie yazykovogo obshcheniya [Computer Linguistics: Modeling Language Communication]. Novoe v zarubezhnoy lingvistike. Vyp. 24. Komp'yuternaya lingvistika [New in foreign linguistics. Vol. 24. Computer linguistics]. Moscow: Progress, 1989. S. 5-31. (In Russian).

Deyk van T.A. Yazyk. Poznanie. Kommunikatsiya [Language. Cognition. Communication]. 2-e izd. Moscow: LENAND, 2015. 320 s. (In Russian).

Zaporozhets A.V. Razvitie proizvol'nykh dvizheniy [The development of voluntary movements]. Moscow: Izd-vo Akademii pedagogicheskikh nauk RSFSR, 1960. 431 s. (In Russian). 
Голышкина Л.А. Текстообразование как ориентировочная деятельность...

Zemskaya Yu.N., Kachesova I.Yu., Panchenko N.V., Chuvakin A.A. Osnovy obshchey ritoriki [Basics of general rhetoric]. Barnaul: Izd-vo Altayskogo universiteta, 2000. $110 \mathrm{~s}$. (In Russian).

Leont'ev A.A. Psikhologiya obshcheniya [Communication psychology]. 2-e izd., ispr. i dop. Moscow: Smysl, 1997. 365 s. (In Russian).

Liders A.G., Frolov Yu.I. Razvitie predstavleniy ob orientirovke i orientirovochnoy deyatel'nosti v kontseptsii P.Ya. Gal'perina [The development of ideas about orientation and orientation activity in the concept of P.Ya. Halperin]. Kul'turno-istoricheskaya psikhologiya [Cultural-historical psychology], 2012, vol. 8, no. 4. S. 13-27. (In Russian).

Mel'chuk I.A. Yazyk: ot smysla k tekstu [Language: from meaning to text]. Moscow: Yazyki slavyanskoy kul'tury, 2012. 176 s. (In Russian).

Podol'skiy A.I. Intellekt $\mathrm{v}$ sisteme orientirovochnoy deyatel'nosti [Intelligence in the system of orientation activity]. Psikhologicheskie issledovaniya intellektual'noy deyatel'nosti [Psychological studies of intellectual activity]. Pod red. O.K. Tikhomirova. Moscow, 1979. S. 204-210. (In Russian).

Podol'skiy A.I. Funktsional'noe razvitie poznavatel'noy deyatel'nosti v usloviyakh ee planomernogo formirovaniya [Functional development of cognitive activity in the conditions of its systematic formation]: dis. ... d-ra psikhol. nauk: 19.00.07. Moscow, 1987. 450 s. (In Russian).

Talyzina N.F. Upravlenie protsessom usvoeniya znaniy [Knowledge Management]. Moscow: Izd-vo MGU, 1975. 344 s.

Tarasov E.F. K postroeniyu teorii rechevoy kommunikatsii [On the construction of the theory of speech communication]. Teoreticheskie i prikladnye problemy rechevogo obshcheniya [Theoretical and applied problems of speech communication]. Moscow: LIBROKOM, 2009. S. 5-147. (In Russian).

Yakobson R.O. Rechevaya kommunikatsiya; Yazyk v otnoshenii k drugim sistemam kommunikatsii [Speech communication; Language in relation to other communication systems]. Izbrannye raboty [Selected works]. Moscow: Progress, 1985. S. 319-330. (In Russian).

Lasswell, H.D. (1948). The Structure and Function of Communication in Society // The Communication of Ideas. New York: Harper and Brothers, 1948, pp. 37-51.

Shannon, C.E. (1948). The Mathematical Theory of Communication // The Bell System Technical Journal. July, 1948, vol. 27, no. 3, pp. 379-423. 